\title{
Aromatics Production from Lignocellulosic Biomass: Shape Selective Dealkylation of Lignin-Derived Phenolics over Hierarchical ZSM-5
}

Yuhe Liao ${ }^{\mathrm{a}}$, Ruyi Zhong, Martin d'Halluinn, Danny Verboekend ${ }^{\mathrm{a}, *}+$, Bert F. Sels ${ }^{\mathrm{a},}{ }^{*}$

${ }^{a}$ Centre for Sustainable Catalysis and Engineering, KU Leuven, Celestijnenlaan 200F, 3001 Heverlee, Belgium

${ }^{\dagger}$ Present address: Zeopore Technologies NV, Lelielaan 4, 3061 Bertem, Belgium

Corresponding Author

*Email: bert.sels@kuleuven.be;

danny.verboekend@kuleuven.be

Number of pages: 17

Number of Tables: 2

Number of Figures: 11 


\section{Experimental Section}

\section{Chemicals and materials}

4- $n$-propylphenol ( $\geq 97 \%), \mathrm{NaOH}(\geq 98 \%), \mathrm{HCl}(37 \%), \mathrm{NH}_{4} \mathrm{NO}_{3}(\geq 98 \%)$ were purchased from Sigma-Aldrich. All chemicals were used as received without further treatment. CBV8014 (ZSM-5, Si/Al=40) was obtained from Zeolyst. Distilled water was used for zeolites modification and dealkylation experiments.

\section{Catalyst preparation}

Post-modification of ZSM-5 was conducted in a round flask with magnetic stirring at $338 \mathrm{~K}$. For the alkaline treatment, $3.3 \mathrm{~g}$ of zeolites were loaded into $100 \mathrm{~mL} \mathrm{NaOH}$ solution under stirring of $500 \mathrm{rpm}$ and the reaction mixture was heated at $338 \mathrm{~K}$ for $0.5 \mathrm{~h}$. Afterwards, the solution was quenched by icy water, followed by filtration, extensive washing with distilled water, and drying at $338 \mathrm{~K}$ overnight. For the acid washing, $1 \mathrm{~g}$ of alkaline treated sample was loaded into $100 \mathrm{~mL} 0.1 \mathrm{M} \mathrm{HCl}$ solution under stirring of $500 \mathrm{rpm}$ and the reaction mixture was heated at $338 \mathrm{~K}$ for $6 \mathrm{~h}$, followed by quenching, filtration, washing with distilled water and drying as the procedure in alkaline treatment. All samples were transformed into protonic form by ion exchanged $(0.1 \mathrm{M}$ $\mathrm{NH}_{4} \mathrm{NO}_{3}$, room temperature, 12 hours, 3 consecutive treatments), followed by calcination at $823 \mathrm{~K}$ for $5.5 \mathrm{~h}$ with a heating rate of $5 \mathrm{~K} \mathrm{~min}^{-1}$ in static air. The modification conditions and the code of all samples used in this work are summarized in Table S1.

\section{Catalyst characterization}

X-ray diffraction (XRD) patterns were obtained by using a STOE STADI MP diffractometer, with $\mathrm{Cu}-\mathrm{Ka}_{1}$ radiation $(\lambda=1.54 \AA)$ and a IP-PSD detector. Nitrogen $\left(\mathrm{N}_{2}\right)$ sorption was conducted on a Micromeritics Tristar instrument at $77 \mathrm{~K}$. Before measurement, the sample was pretreated at $573 \mathrm{~K}$ under a $\mathrm{N}_{2}$ flow for $6 \mathrm{~h}$. The tplot was used to determine the external surface area $\left(S_{\text {meso }}\right.$, including external surface area and mesopore surface area) and micropores volume $\left(V_{\text {micro }}\right)$. The total pore volume $\left(V_{\text {pore }}\right)$ was determined by the adsorption value at $p / p_{0}=0.97$. The $\mathrm{BJH}$ model was applied to the adsorption branch to determine the pore size distribution. Pyridine FTIR on a Nicolet 6700 spectrometer equipped with a DTGs detector was used to determine Brønsted and Lewis acid density. All measurements, including the background, and the sample before and after exposure to pyridine were conducted at $423 \mathrm{~K}$. In a typical procedure, the measurement cell was pretreated at $673 \mathrm{~K}$ for $5 \mathrm{~h}$ under $1 \mathrm{mbar}$, the background was then recorded. The samples were pressed into self-supported wafers and the later were pretreated at $673 \mathrm{~K}$ for $1 \mathrm{~h}$ under $1 \mathrm{mbar}$ in order to remove some adsorb molecules, the FTIR spectra of the sample before exposure to pyridine was recorded. The sample was then subjected to 20-25 mbar pyridine vapor until saturation at $323 \mathrm{~K}$. The pyridine was desorbed at different temperatures $(423$, 523 , and $623 \mathrm{~K}$ ) for $20 \mathrm{~min}$ and the FTIR spectra were all recorded at $423 \mathrm{~K}$. The heating rate was $5 \mathrm{~K} \mathrm{~min}^{-1}$. The bands at 1545 (Brønsted acid sites) and $1455 \mathrm{~cm}^{-1}$ (Lewis acid sites) were integrated and used to quantify the acid density with the molar extinction coefficients proposed by Emeis. ${ }^{1} \mathrm{NH}_{3}$-TPD was conducted in a flow instrument equipped with a mass spectrometer to monitor the desorbed gas $\left(\mathrm{NH}_{3}\right)$. Typically, $100 \mathrm{mg}$ of sample $\left(0.125-0.25 \mathrm{~mm}\right.$ ) was pretreated at $673 \mathrm{~K}$ (heating rate: $5 \mathrm{~K} \mathrm{~min}^{-1}$ ) in a helium flow for $2 \mathrm{~h}$. The sample was contacted with $\mathrm{NH}_{3}$ for $0.5 \mathrm{~h}$ after the temperature was cooled to $473 \mathrm{~K}$. Excessive $\mathrm{NH}_{3}$ was flushed away by He flow at $473 \mathrm{~K}$ for $0.5 \mathrm{~h}$. Then the $\mathrm{NH}_{3}$-TPD profiles $\left(\mathrm{NH}_{3}, \mathrm{~m} / \mathrm{e}=16\right)$ were recorded by increasing the temperature to $973 \mathrm{~K}$ at $10 \mathrm{~K} \mathrm{~min}^{-1}$ in a helium flow. The signal of $\mathrm{m} / \mathrm{e}=17$ in the mass spectrometer is strongly influenced by water, while $\mathrm{m} / \mathrm{e}=16$ is normally affected by an oxygen-containing substance such as carbon dioxide. ${ }^{2}$ The signal of $\mathrm{m} / \mathrm{e}=15$ is very week compared to $\mathrm{m} / \mathrm{e}=16$ in our measurements. Therefore, $\mathrm{m} / \mathrm{e}=16$ was used to estimate the acidity of ZSM- 5 in this work. Thermo-gravimetric analysis (TGA) was conducted on a TGA-Q500 analyzer. The measurements were carried out in air flow with increasing the temperature from room temperature $(\mathrm{ca} .300 \mathrm{~K})$ to $1073 \mathrm{~K}$ at $10 \mathrm{~K} \mathrm{~min}^{-1}$. 


\section{Catalytic test}

Dealkylation of 4-n-propylphenol (4-n-PP) was conducted in a gas-phase fixed-bed reactor, equipped with four glass reactor tubes (inner diameter: $3 \mathrm{~mm}$ ). In a typical experiment, the catalyst was pelletized and sieved between 0.125 and $0.25 \mathrm{~mm} .30 \mathrm{mg}$ of catalyst was loaded into the reactor tube. 4-n-PP and water were introduced into reactor by using $\mathrm{N}_{2}$ through the heated saturators. They were mixed before reaction, generating a molar composition: $\mathrm{N}_{2} / \mathrm{H}_{2} \mathrm{O} / 4-n-\mathrm{PP}=86 / 12 / 2$. The products were analysed by an on-line GC (HP-4890D) equipped with a HP1 column and a Flame Ionization Detector (FID). For the high WHSV experiments, the catalyst loading was reduced (to $2 \mathrm{mg}$ ) and it was mixed with quartz powder (inert material, $0.125-0.25 \mathrm{~mm}$ ) to yield the same bed height as in the low WHSV measurements. The gas flow and composition were same in both cases. The reliability of light-off experiments (catalytic evaluation with increasing the temperature at $1 \mathrm{~K}$ $\mathrm{min}^{-1}$ from $473 \mathrm{~K}$ to $743 \mathrm{~K}$ ) with ZSM-5-P has been demonstrated in our previous work by using reverse lightoff experiments (decreasing the temperature from $743 \mathrm{~K}$ to $473 \mathrm{~K}$ with $1 \mathrm{~K} \mathrm{~min}^{-1}$ ) and time on stream test on single temperature. ${ }^{3-4}$ Similarly, the reliability was also shown in this work by using time on stream on single temperature (Figure 2, the star symbols). For the kinetic study, the diffusion limitations (in the kinetic regime) in ZSM-5, including external and internal (inter- and intra-crystal), were excluded by using control experiments (with changing catalyst particle size and flow) and Mears and Weisz-Prater criteria. ${ }^{3-4}$

\section{Iterative approach to investigate the activity of Brønsted acid sites and Lewis acid sites and the influence of acid strength}

To investigate the influence of acid strength on the catalytic performance, the numbers of Brønsted and Lewis acid sites measured at $423 \mathrm{~K}$ and $523 \mathrm{~K}$ were used to fit the data by an iterative approach.

$$
\text { Rate }=k=\chi \times k_{B A}+\mathrm{y} \times k_{L A}
$$

where $k$ is observed rate, $\mathrm{mol} \mathrm{s}^{-1} ; k_{B A}$ is rate of Brønsted acid sites, $\mathrm{mol} \mathrm{s}{ }^{-1} ; k_{L A}$ is the rate of Lewis acid sites, mol s ${ }^{-1} ; \chi$ is coefficient of Brønsted acid sites; $y$ is coefficient of Lewis acid sites.

$$
k_{B A}=N_{B A} \times A_{B A} \times e^{-\frac{E a_{B A}}{R T}}
$$

where $N_{B A}$ is the number of $\mathrm{Br} ø$ nsted acid sites, $\mathrm{mol} \mathrm{g}^{-1}$; $A_{B A}$ is the pre-exponential factor of Brønsted acid sites, $\operatorname{Ln}\left(A_{B A}\right)=14.9 \mathrm{~mol} \mathrm{~mol}_{\text {acid sites }}^{-1} s^{-1} ; E a_{B A}$ is the activation energy of Brønsted acid sites, $91 \mathrm{~kJ} \mathrm{~mol}^{-1} ; R$ is the gas constant, $8.314 \mathrm{~J} \mathrm{~mol}^{-1} \mathrm{~K}^{-1}$; $T$ is the reaction temperature, $\mathrm{K}$.

$$
k_{L A}=N_{L A} \times A_{L A} \times e^{-\frac{E a_{L A}}{R T}}
$$

where $N_{L A}$ is the number of Lewsi acid sites, $\mathrm{mol} \mathrm{g}^{-1} ; A_{L A}$ is the pre-exponential factor of Lewis acid sites, $\operatorname{Ln}\left(A_{L A}\right)=21.0 \mathrm{~mol} \mathrm{~mol}_{\text {acid sites }}^{-1} s^{-1} ; E a_{L A}$ is the activation energy of Lewis acid sites, $116 \mathrm{~kJ} \mathrm{~mol}^{-1}$; $R$ is the gas constant, $8.314 \mathrm{~J} \mathrm{~mol}^{-1} \mathrm{~K}^{-1}$; $T$ is the reaction temperature, $\mathrm{K}$.

\section{The empirical formula for fitting the activity decay}

An empirical formula of zeolites deactivation was used to fit the activity decay of ZSM-5: - $^{5-6}$

$$
\frac{X_{t}}{X_{0.25}}=a e^{-b t}-c t+d
$$

where $X_{\mathrm{t}}$ is the conversion at reaction time $\mathrm{t} ; X_{0.25}$ is the conversion at reaction time $0.25 \mathrm{~h} ; a$ is a constant, which refers to the number of strong active sites in the zeolites; $b$ is related to the deactivation rate of strong active sites caused by coking, $\mathrm{h}^{-1} ; \mathrm{c}$ is related to the formation rate of coke or bulky products at the micropore mouth 
and in the micropores, which diminishes the catalytic activity and ultimately blocks the micropore channel, $\mathrm{h}^{-1}$; $d$ is a constant, which represents the number of strong active sites that never deactivates in the zeolites. 
Table S1. Post-modification conditions and materials yield for ZSM-5 modification.

\begin{tabular}{ccccccccc}
\hline Parent material & Reagent & $C / \mathrm{M}$ & $C_{\text {zeolite }} / \mathrm{gL}^{-1}$ & $\mathrm{~T} / \mathrm{K}$ & $\mathrm{t} / \mathrm{h}$ & Code $^{a}$ & Yield / \% & Ref. \\
\hline CBV8014 & - & 0 & - & - & - & ZSM-5-P & 100 & - \\
ZSM-5-P & $\mathrm{NaOH}$ & 0.1 & 33 & 338 & 0.5 & ZSM-5-H-0.1M & 80 & 7 \\
ZSM-5-P & $\mathrm{NaOH}$ & 0.2 & 33 & 338 & 0.5 & ZSM-5-H-0.2M & 57 & 7 \\
ZSM-5-P & $\mathrm{NaOH}$ & 0.3 & 33 & 338 & 0.5 & ZSM-5-H-0.3M & 42 & 7 \\
ZSM-5-P & $\mathrm{NaOH}$ & 0.4 & 33 & 338 & 0.5 & ZSM-5-H-0.4M & 33 & 7 \\
ZSM-5-H-0.2M & $\mathrm{HCl}$ & 0.1 & 10 & 338 & 6 & ZSM-5-H-0.2M-HCl & $51(89)^{b}$ & 7
\end{tabular}

${ }^{a}$ All samples were transferred into protonic form; ${ }^{b}$ Value in the bracket is the yield based on the ZSM-5-H-0.2M. 

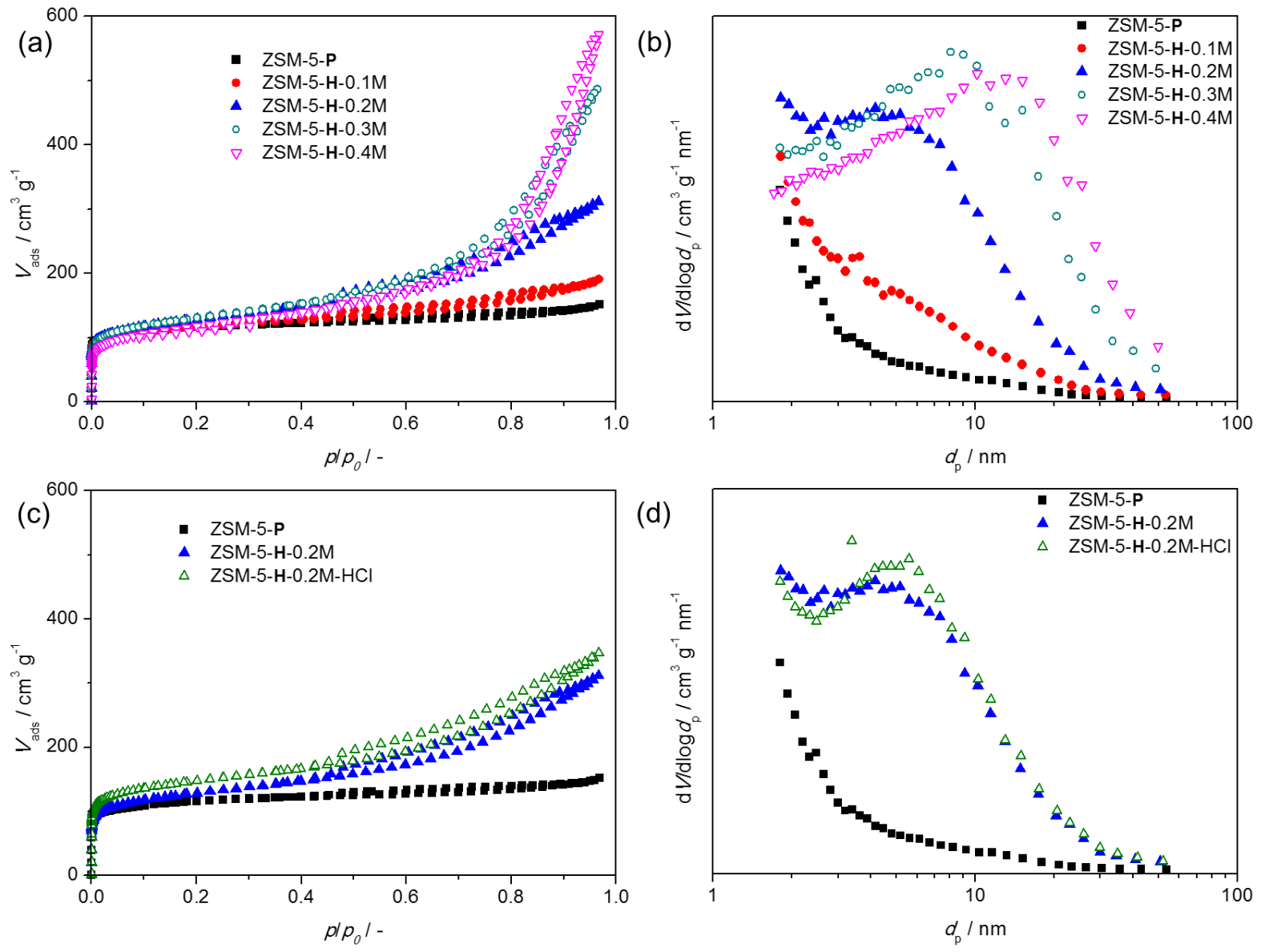

Figure S1. $\mathrm{N}_{2}$ isotherms (a, c) and pore size distribution (b, d) of ZSM-5-P and ZSM-5-H. 

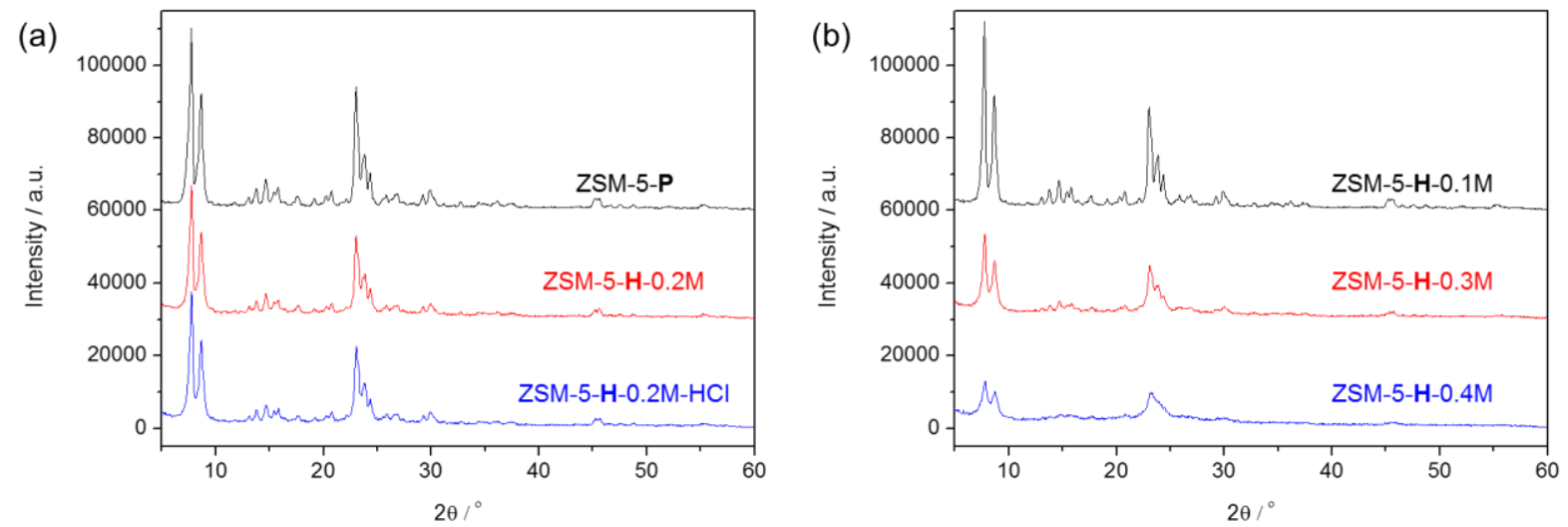

Figure S2. X-ray diffraction patterns of ZSM-5-P and ZSM-5-H. 

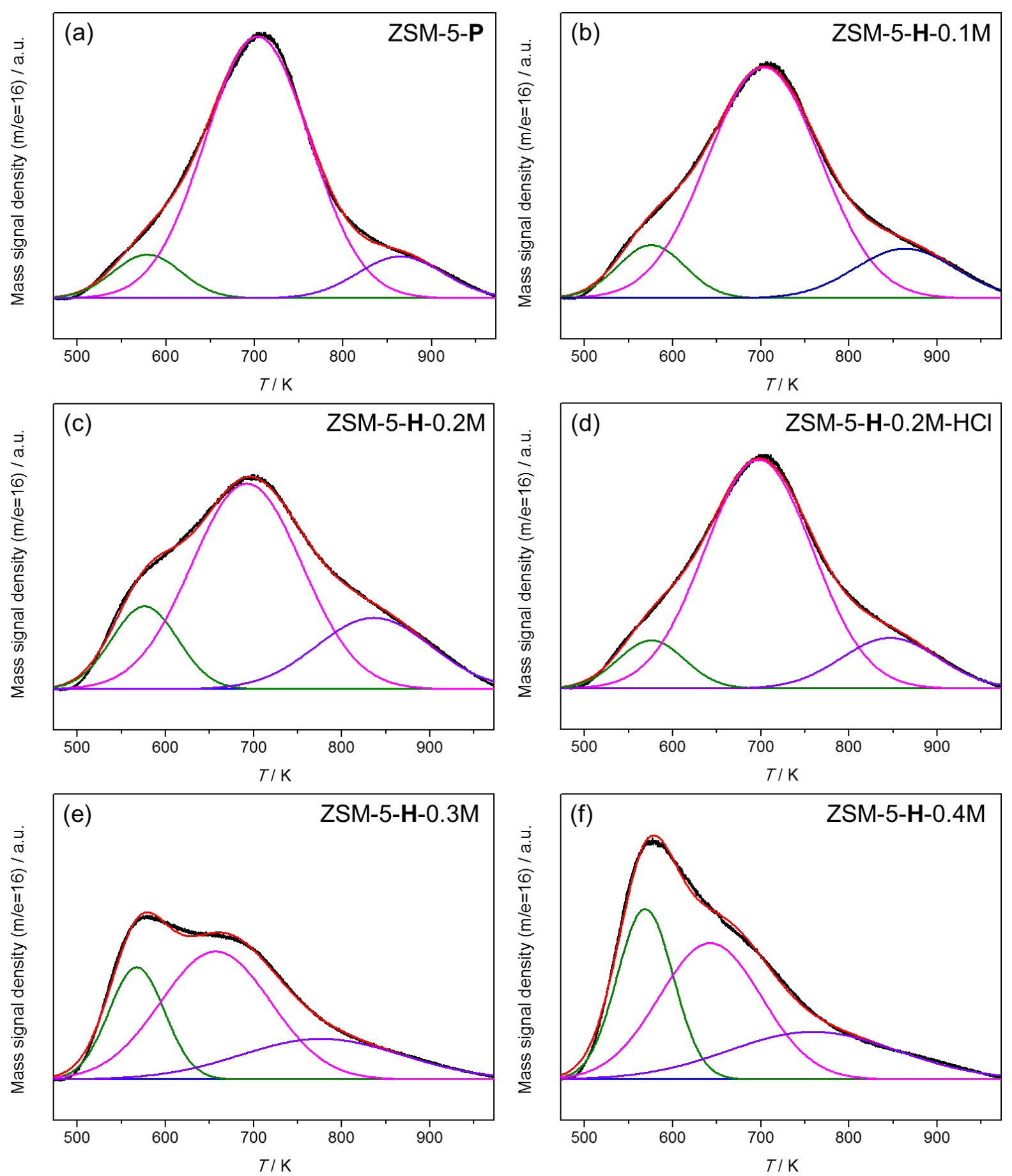

Figure S3. $\mathrm{NH}_{3}-\mathrm{TPPD}$ profiles of ZSM-5-P and ZSM-5-H. 
Table S2. The percentage of $\mathrm{NH}_{3}$ desorbed at different temperature range. ${ }^{a}$

\begin{tabular}{cccc}
\hline Sample & $T_{573} / \%$ & $T_{703} / \%$ & $T_{863} / \%$ \\
\hline ZSM-5-P & 8.7 & 80.8 & 10.5 \\
ZSM-5-H-0.1M & 10.3 & 75.3 & 14.4 \\
ZSM-5-H-0.2M & 15.1 & 62.5 & 22.4 \\
ZSM-5-H-0.2M-HCl & 9.7 & 75.4 & 14.9 \\
ZSM-5-H-0.3M & 23.3 & 52.5 & 24.2 \\
ZSM-5-H-0.4M & 30.4 & 44.2 & 25.4 \\
\hline
\end{tabular}

${ }^{a}$ Data were calculated from the area of the resolved TPD peaks. 

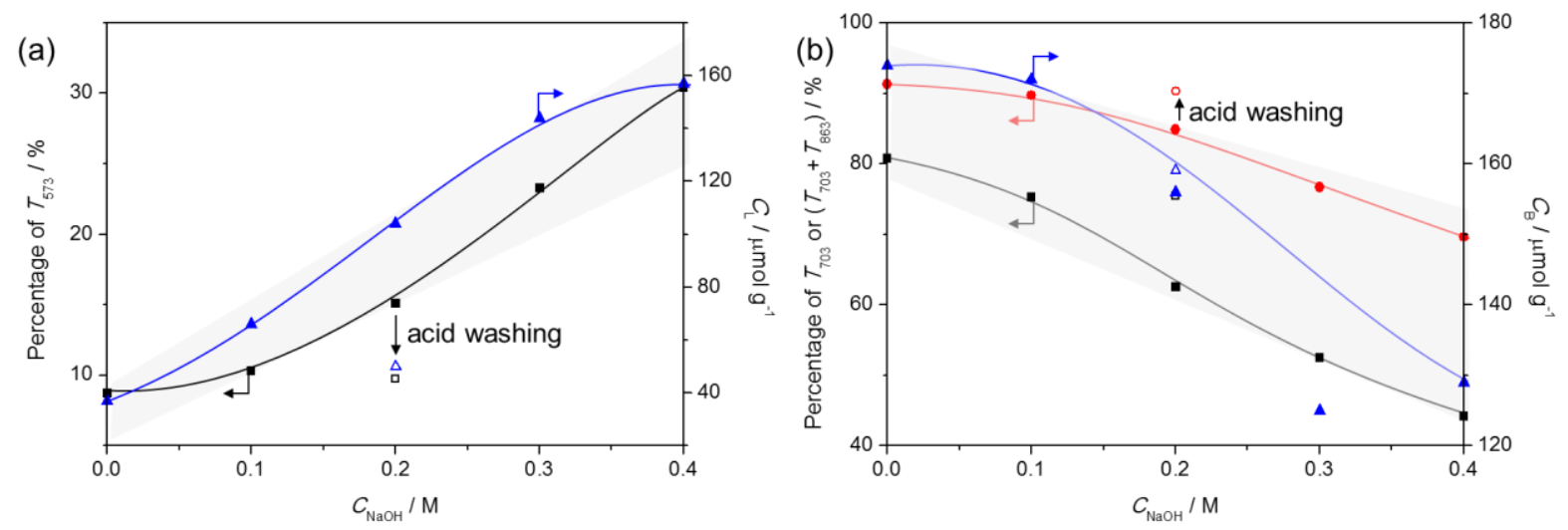

Figure S4. (a) Percentage of $T_{573}$ (determined by $\mathrm{NH}_{3}-\mathrm{TPD}$ ) and $\mathrm{C}_{\mathrm{L}}$ (determined by pyridine FTIR at $423 \mathrm{~K}$ ) as a function of $C_{\mathrm{NaOH}}$; (b) Percentage of $T_{703}$ and $\left(T_{703}+T_{863}\right)$ (determined by $\mathrm{NH}_{3}-\mathrm{TPD}$ ) and $\mathrm{C}_{\mathrm{B}}$ (determined by pyridine FTIR $423 \mathrm{~K}$ ) as a function of $C_{\mathrm{NaOH}}$. $C_{\mathrm{L}}$ : density of Lewis acid sites; $C_{\mathrm{B}}$ : density of Brønsted acid sites; $C_{\mathrm{NaOH}}$ : concentration of $\mathrm{NaOH}$ used for alkaline treatment. 

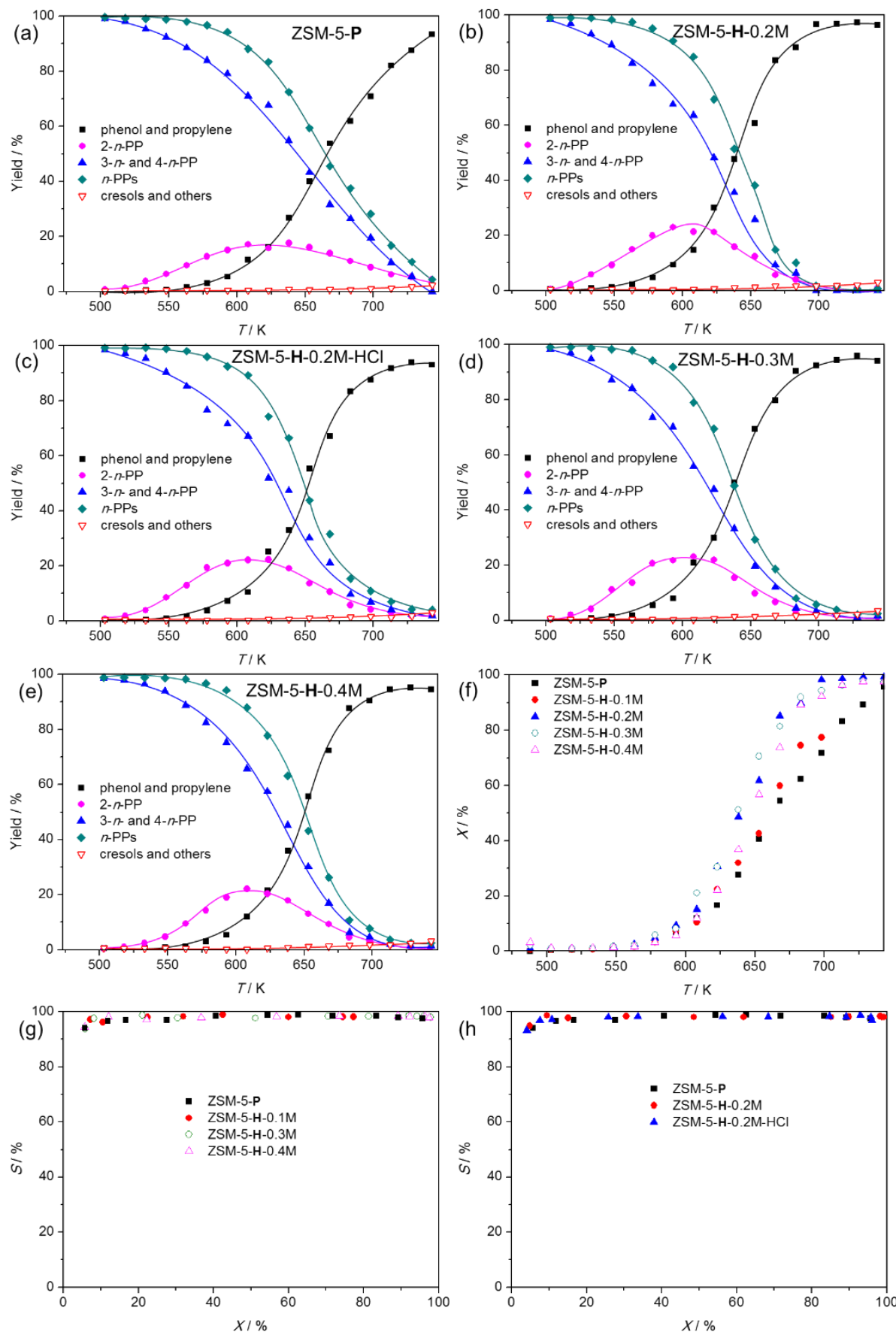

Figure S5. Products distribution as a function a temperature $(T)$ in dealkylation of 4- $n$-PP over ZSM-5-P (a), ZSM-5-H-0.2M (b), ZSM-5-H-0.2M-HCl (c), ZSM-5-H-0.3M (d), ZSM-5-H-0.4M (e); (f) Conversion (X) of $n$-PPs as a function of temperature $(T) ;(\mathrm{g})$ and $(\mathrm{h})$ the selectivity $(S)$ to phenol and propylene as a function of conversion $(X)$ of $n$-PPs. In $(\mathrm{g})$ and $(\mathrm{h})$, the conversion was changed by rising the reaction temperature. Reaction conditions: $55.5 \mathrm{~h}^{-1} \mathrm{WHSV}$, ramping rate $=1 \mathrm{~K} \mathrm{~min}^{-1}$, water/4-n-PP=6. Note: the molar ratio of propylene to phenol is about one as we demonstrated in our previous work. ${ }^{4}$ Besides, the selectivity to propylene in the total gas (uncondensed in the cold trap) is higher than $97 \%$. 


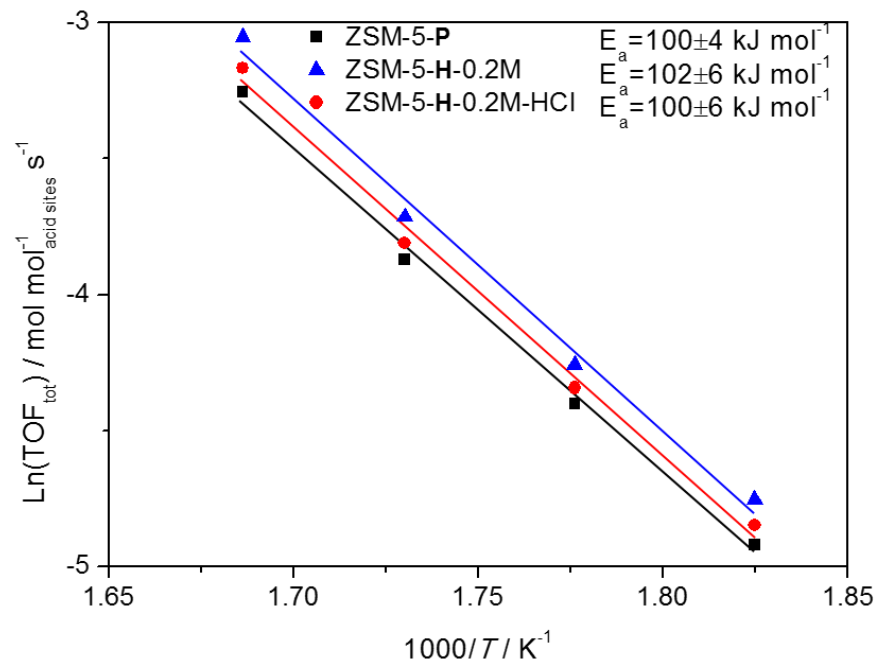

Figure S6. Turnover frequency (TOF) of $n$-PPs dealkylation over ZSM-5-P, ZSM-5-H-0.2M, and ZSM-5-H$0.2 \mathrm{M}-\mathrm{HCl}$ at $55.5 \mathrm{~h}^{-1} \mathrm{WHSV}$ based on total number of acid sites (measured at $523 \mathrm{~K}$ by pyridine FTIR), with indication of activation energy. 

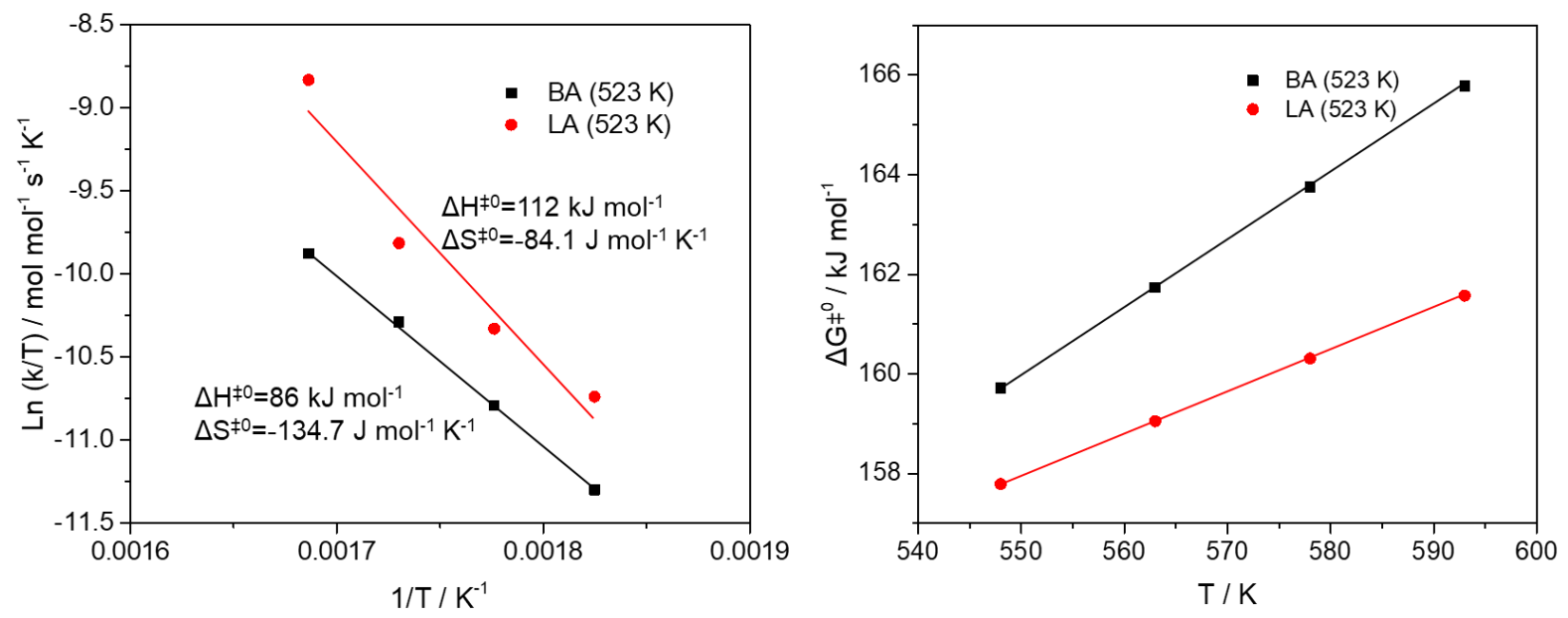

Figure S7. Eyring plot of Brønsted acid (BA) sites and Lewis acid (LA) sites. This plot is related to Arrhenius plot in Figure 3b. 

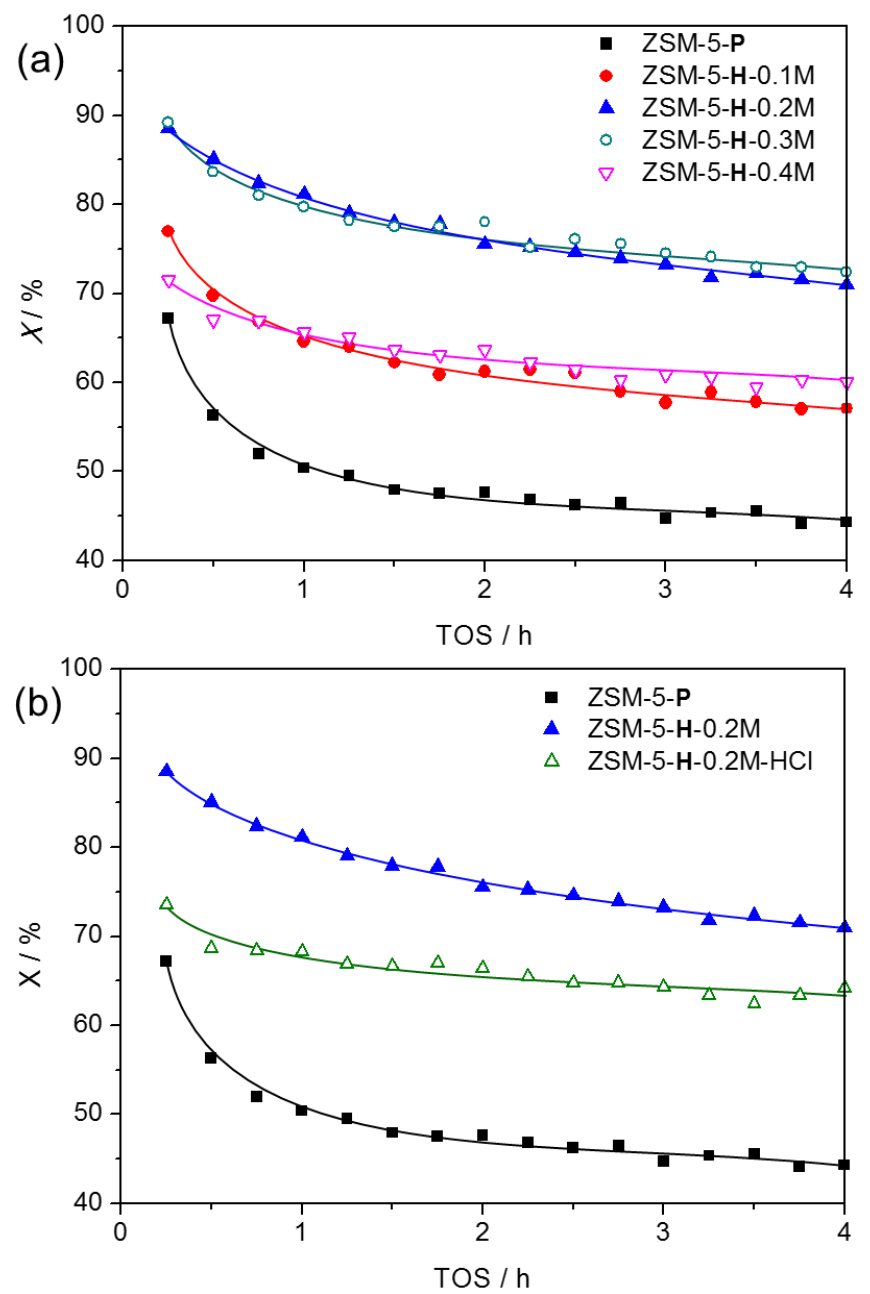

Figure S8. (a) Conversion $(X)$ of $n$-PPs and selectivity $(S)$ to phenol and propylene as a function of time on stream (TOS) in the dealkylation of 4- $n$-PP over ZSM-5-P and ZSM-5-H. WHSV $=55.5 \mathrm{~h}^{-1}$, temperature $658 \mathrm{~K}$, water $/ 4-n-\mathrm{PP}=6$. 

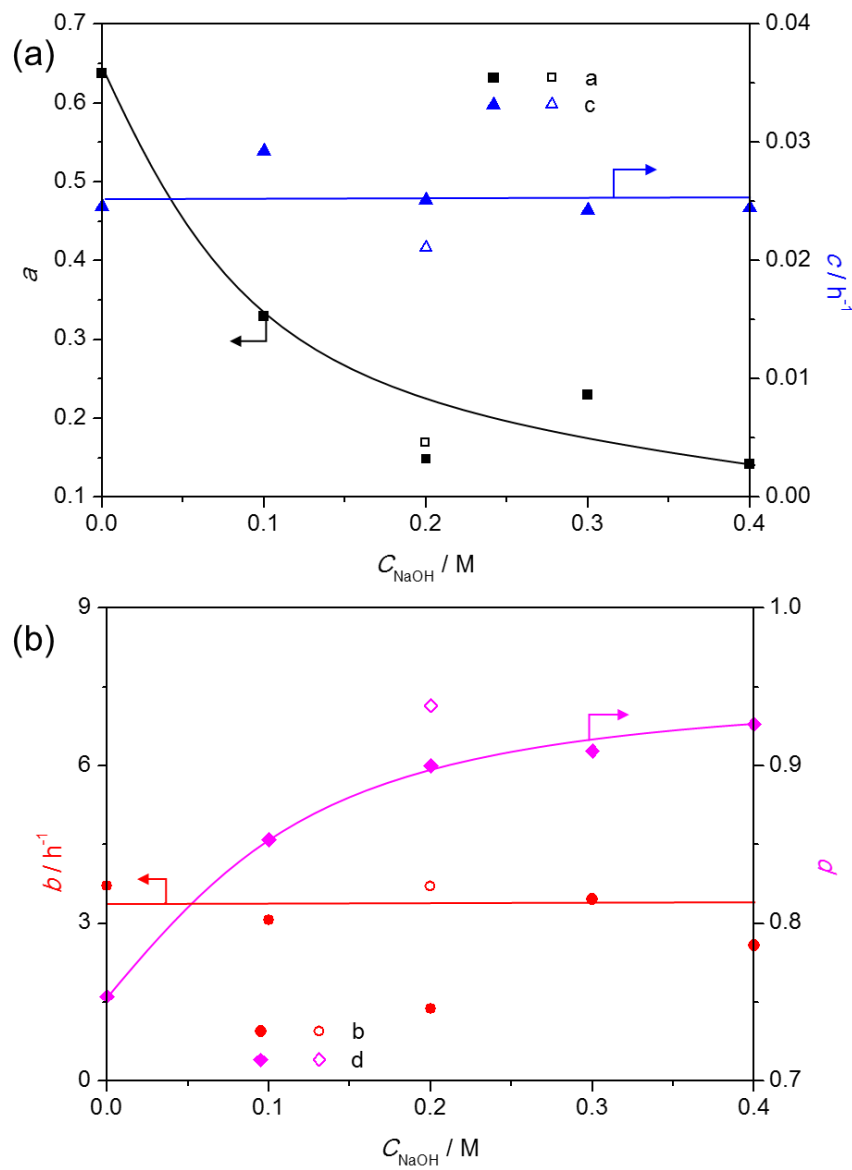

Figure S9. The value of parameters of empirical formula (equation 4, experimental section) as a function of the alkaline concentration used for post-modification of ZSM-5. These data were adapted from Figure 4. 


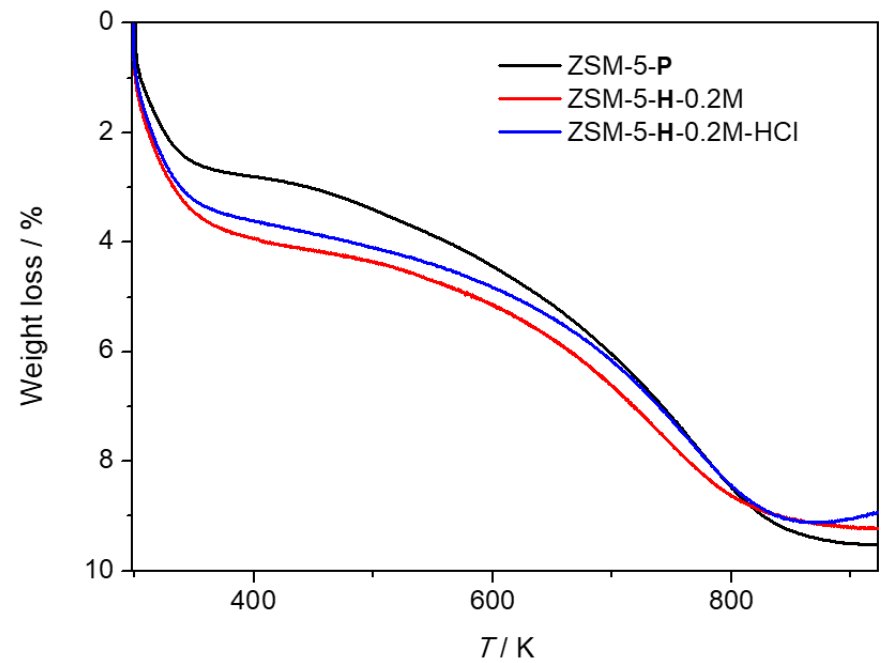

Figure S10. Thermo-gravimetric analyses (TGA) of spent ZSM-5-P, ZSM-5-H-0.2M, and ZSM-5-H-0.2M$\mathrm{HCl}$ obtained from dealkylation experiments in the presence of water. 

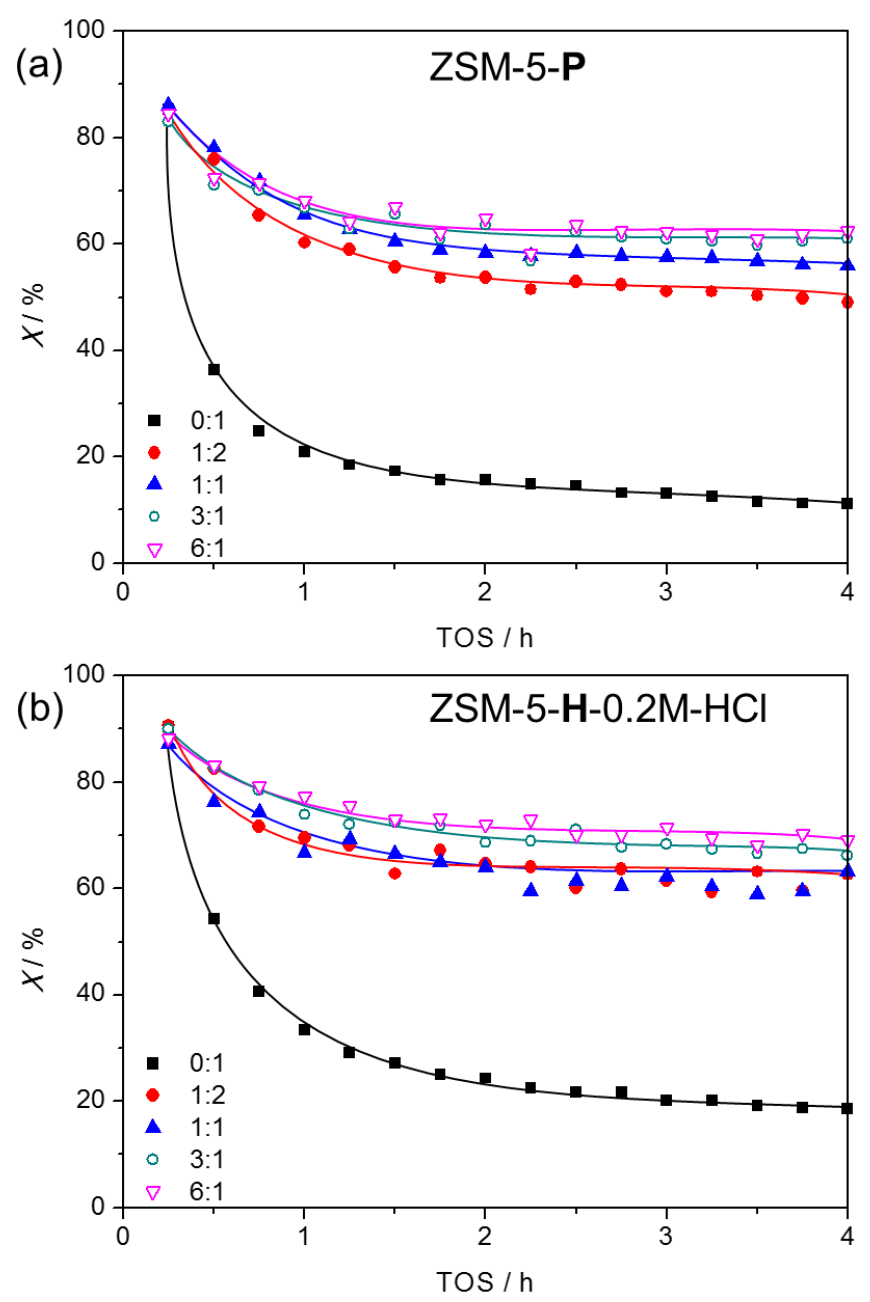

Figure S1 1. Conversion $(X)$ of $n$-PPs as a function of time on stream (TOS) in the dealkylation of 4- $n$-PP over ZSM-5-P and ZSM-5-H-0.2M-HCl at different water/4-n-propylphenol ratio. WHSV $=3.7 \mathrm{~h}^{-1}, 578 \mathrm{~K}$. 


\section{Reference}

1. Emeis, C., Determination of integrated molar extinction coefficients for infrared absorption bands of pyridine adsorbed on solid acid catalysts. J. Catal. 1993, 141, 347-354. 10.1006/jcat.1993.1145.

2. Katada, N.; Niwa, M., Analysis of acidic properties of zeolitic and non-zeolitic solid acid catalysts using temperature-programmed desorption of ammonia. Catal. Surv. Asia 2004, 8, 161-170. 10.1023/B:CATS.0000038534.37849.16.

3. Liao, Y.; d'Halluin, M.; Makshina, E.; Verboekend, D.; Sels, B. F., Shape selectivity vapor-phase conversion of lignin-derived 4-ethylphenol to phenol and ethylene over acidic aluminosilicates: impact of acid properties and pore constraint. Appl. Catal. B: Environ. 2018, 234, 117-129. 10.1016/j.apcatb.2018.04.001.

4. Liao, Y.; Zhong, R.; Makshina, E.; d'Halluin, M.; Limbergen, Y.; Verboekend, D.; Sels, B. F., Propylphenol to phenol and propylene over acidic zeolites: role of shape selectivity and presence of steam. ACS Catal. 2018, 8, 7861-7878. 10.1021/acscatal.8b01564.

5. Reyes, S. C.; Scriven, L., Analysis of zeolite catalyst deactivation during catalytic cracking reactions. Ind. Eng. Chem. Res. 1991, 30 (1), 71-82. 10.1021/ie00049a011.

6. Santacesaria, E.; Di Serio, M.; Ciambelli, P.; Gelosa, D.; Carra, S., Catalytic alkylation of phenol with methanol: Factors influencing activities and selectivities: II. Effect of intracrystalline diffusion and shape selectivity on H-ZSM5 zeolite. Appl. Catal. 1990, 64, 101-117. 10.1016/S0166-9834(00)81556-0.

7. Milina, M.; Mitchell, S.; Michels, N. L.; Kenvin, J.; Perez-Ramirez, J., Interdependence between porosity, acidity, and catalytic performance in hierarchical ZSM-5 zeolites prepared by post-synthetic modification. J. Catal. 2013, 308, 398-407. 10.1016/j.jcat.2013.08.020. 